\title{
Terminations of pregnancy in the European Union
}

\author{
M Gissler, ${ }^{\mathrm{a}, \mathrm{b}}$ I Fronteira, ${ }^{\mathrm{c}}$ A Jahn, ${ }^{\mathrm{d}} \mathrm{H}$ Karro, ${ }^{\mathrm{e}} \mathrm{C}$ Moreau, ${ }^{\mathrm{f}}$ M Oliveira da Silva, ${ }^{\mathrm{g}} \mathrm{J}$ Olsen, ${ }^{\mathrm{h}}$ \\ C Savona-Ventura, ${ }^{i}$ M Temmerman, ${ }^{j}$ E Hemminki, ${ }^{a}$ the REPROSTAT group
}

${ }^{a}$ Information Department, THL National Institute for Health and Welfare, Helsinki, Finland ${ }^{\mathrm{b}}$ Nordic School of Public Health, Gothenburg, Sweden ${ }^{\mathrm{c}}$ Instituto de Higiene e Medicina Tropical, Universidade Nova de Lisboa, Lisbon, Portugal ${ }^{\mathrm{d}}$ Institution of Public Health, University of Heidelberg, Heidelberg, Germany ${ }^{\mathrm{e}}$ Women's Clinic, University of Tartu, Tartu, Estonia ${ }^{\mathrm{f}}$ Faculty of Medicine, University of Lisbon, Lisbon, Portugal ${ }^{g}$ Gender, Sexual and Reproductive Health, CESP Centre for Research in Epidemiology and Population Health, Villejuif, France ${ }^{h}$ Institution of Epidemiology and Social Medicine, University of Århus, Århus, Denmark ${ }^{i}$ Faculty of Medicine and Surgery, Department of Obstetrics and Gynaecology, University of Malta, Msida, Malta ${ }^{j}$ Obstetrics and Gynaecology, Ghent University, Ghent, Belgium Correspondence: Dr M Gissler, THL National Institute for Health and Welfare, PO Box 30, 00271 Helsinki, Finland. Email mika.gissler@thl.fi

Accepted 18 September 2011. Published Online 30 November 2011.

Objective To study the current legislation and trends in terminations of pregnancy in the European Union (EU).

Design Data were collected on legislation and statistics for terminations of pregnancy.

Setting Population-based statistics from the EU member states.

Population Women in reproductive age in the $27 \mathrm{EU}$ member states.

Methods Information on legislation was collected for all $27 \mathrm{EU}$ member states. Statistical information until 2008 was compiled from international $(n=24)$ and national sources $(n=17)$. Statistical data were not available for Austria, Cyprus and Luxembourg.

Main outcomes measures Terminations of pregnancy per 1000 women aged 15-49 years.

Results Ireland, Malta and Poland have restrictive legislation. Luxembourg permits termination of pregnancy on physical and mental health indications; Cyprus, Finland, and the UK further include socio-economic indications. In all other EU member states termination of pregnancy can be performed in early pregnancy on a women's request. In general, the rates of termination of pregnancy have declined in recent years. In total, 10.3 terminations were reported per 1000 women aged $15-49$ years in the EU in 2008. The rate was $12.3 / 1000$ for countries requiring a legal indication for termination, and 11.0/1000 for countries allowing termination on request. Northern Europe (10.9/1000) and Central and Eastern Europe (10.8/1000) had higher rates than Southern Europe (8.9/1000). Northern Europe, however, had substantially higher rates of termination of pregnancy among teenagers.

Conclusion A more consistent and coherent reporting of terminations of pregnancy is needed in the EU. The large variation of termination rates between countries suggests that termination of pregnancy rates may be reduced in some countries without restricting women's access to termination. Sexual education and provision of access to reliable and affordable contraception are essential to achieve low rates of termination of pregnancy.

Keywords Abortion statistics, legislation, reproductive and sexual health, termination of pregnancy.

Please cite this paper as: Gissler M, Fronteira I, Jahn A, Karro H, Moreau C, Oliveira da Silva M, Olsen J, Savona-Ventura C, Temmerman M, Hemminki E, the REPROSTAT group. Terminations of pregnancy in the European Union. BJOG 2012;119:324-332.

\section{Introduction}

The frequency of terminations of pregnancy is an important public health indicator, ${ }^{1,2}$ relating primarily to legislation and attitudes towards termination both in society and among individual citizens. ${ }^{3,4}$ Low rates are generally associated with good access to high-quality sexual and reproductive health services, and good availability and appropriate use of effective methods of contraception. The official termination of pregnancy rates also reflect the accuracy of reporting, which varies from country to country.

The European Union (EU) currently consists of 27 member states, which have different traditions, attitudes and legislation related to pregnancy termination. Northern European, generally Protestant, countries introduced easily available legal termination of pregnancy in the early 1970s. The total fertility rate initially declined below the renewal level in these countries earlier than elsewhere in Europe, partly reflecting delayed childbearing. Later, the fertility 
rates in Northern Europe increased, and the rates in the Nordic countries, ${ }^{5}$ and in France, are now the highest in the EU. Such trends suggest that access to termination of pregnancy has not modified the wish for a given family size, but has delayed procreation.

In Western and Southern European, mostly Catholic countries, access to legal terminations of pregnancy has been more restricted, and they are less likely to be available on the woman's request. Excluding Ireland, the total fertility rate has been and remains relatively low in these countries. ${ }^{6}$

The Central and Eastern European countries were the first to legalise terminations of pregnancy. Womanrequested terminations have been available in Hungary since 1953; in the former Soviet Union (including Estonia, Latvia and Lithuania) they have been available since 1955; in Poland and Bulgaria they have been available since 1956; in Czechoslovakia (now the Czech Republic and the Slovak Republic) and Romania they have been available since 1957; and in the former Yugoslavia (including Slovenia) they have been available since $1977^{7,8}$ During the Communist era, both the termination of pregnancy and total fertility rates were substantially higher than elsewhere in Europe. Since then, the legislation has remained unchanged in most of these countries, with the exception of Poland, which introduced very restrictive legislation in $1993 .{ }^{9}$ The termination of pregnancy rates in Central and Eastern Europe have decreased in connection with the improved availability and reliance on modern contraceptives, but also the total fertility rates have dropped partly because of the postponement of childbearing. ${ }^{10}$

We present the legislation on terminations of pregnancy in the $27 \mathrm{EU}$ member states. Based on international and national statistics on terminations of pregnancy, we explore trends in the reported rates of termination of pregnancy in the total population, and have further divided legislation, background factors, and different regions of the EU for more in-depth analysis. We had no data on illegal or other unreported terminations of pregnancy.

\section{Methods}

The State of Reproductive Health and Fertility in the European Union (REPROSTAT 3) project, funded by the EU Health Programme, comprises a group of experts with at least one representative from each EU member state. Each national expert (see the Acknowledgements) was in charge of collecting both detailed reproductive health information and national statistics on reproductive and sexual health for the project. Statistical data on terminations of pregnancy included the number of legal terminations, further broken down by age, parity, previous terminations, gestational age, country of residence, last pregnancy, and migrant/ethnic background.
The contacts surveyed all relevant information on the legislation of termination of pregnancy in their country, and interpreted the data according to a common scheme made by the research group.

The primary sources of statistical information were international statistics on terminations of pregnancy. The data compiled and distributed by Eurostat, ${ }^{11}$ the WHO Regional Office for Europe, ${ }^{12}$ and the United Nations ${ }^{13}$ covered 24 EU member states. Furthermore, 17 EU member states provided at least some additional statistical information on terminations of pregnancy: Belgium, the Czech Republic, Estonia, Finland, France, Greece, Hungary, Ireland, Italy, Lithuania, Malta, Portugal, Romania, the Slovak Republic, Slovenia, Spain, and the UK. Portugal was the only country for which only national data was available. National data for the Slovak Republic was used instead of international data because of an important limitation in the international statistics observed by the country expert. The population figures were based on demographic statistics compiled and published by Eurostat. ${ }^{14}$ Our final statistical data covered information on all EU member states except three countries (Austria, Cyprus, and Luxembourg) that had no statistics on terminations of pregnancy. Both national and international data referred to terminations of pregnancy in calendar-year time periods.

The total number of terminations of pregnancy was calculated per 1000 women aged 15-49 years. We separately present age-specific data for women aged $<20$ years and for women aged 35 years or more. The age-specific rates were calculated per 1000 women aged $15-19$ years and 35-49 years in the population, respectively.

The numbers of termination of pregnancy among women with no previous births, women with four or more previous births, and women with at least one previous termination are presented as a fraction of all terminations of pregnancy. We further calculated the percentage of all terminations of pregnancy at second trimester or later (from $12+0$ weeks of gestation), and the percentage of terminations of pregnancy among women who were not living in the country where the procedure was performed. Information on terminations of pregnancy by migrant or ethnic background was only sporadically available, and the results are not presented here.

To study regional disparities in terminations of pregnancy, the $22 \mathrm{EU}$ member states with legal access to terminations of pregnancy and information on them were divided into three groups, according to their geopolitical and cultural characteristics.

- Northern Europe: Belgium, Denmark, Finland, France, Germany, the Netherlands, Sweden, and the UK.

- Southern Europe: Greece, Italy, Portugal, and Spain.

- Central and Eastern Europe (including the Baltic countries): Bulgaria, the Czech Republic, Hungary, Estonia, 
Latvia, Lithuania, Poland, Romania, the Slovak Republic, and Slovenia.

The following sexual and reproductive health indicators, collected from national and international sources by the REPROSTAT project, are presented in Appendix S1: mean maternal age, total fertility rate, and use of contraceptive. No information was available on unplanned pregnancies, but teenage birth rate and teenage pregnancy rate (including births and terminations of pregnancy) are given as a proxy measure of unplanned pregnancies. The statistical data is described in more detail elsewhere. ${ }^{15}$

\section{Results}

\section{Legislation}

Termination of pregnancy has been prohibited in Ireland since 1861 (excluding situations where the life of the women is at risk) and in Malta since 1724 (in all circumstances), but is legally available elsewhere in the EU under certain conditions. The $25 \mathrm{EU}$ member states with access to termination were divided into four groups according to their legislation. ${ }^{9,16}$

1 Poland allows termination of pregnancy for indications related to fetal abnormality, serious maternal health risks, and for pregnancies resulting from reported rape or other acts of violence (current legislation 1993/ 1997).

2 Spain (1985) and Luxembourg (1978) allow termination of pregnancy for indications related to physical and mental health (since July 2010; however, termination of pregnancy on a woman's request has been available in Spain).

3 Three member states allow terminations of pregnancy for legal indications related to physical and/or mental health or socio-economic reasons: Cyprus (1974/1986), Finland (1970/1978/1985), and the UK (1967/1990), excluding Northern Ireland, where termination of pregnancy is only available in cases of a non-viable fetus, a fetal abnormality, and in cases where maternal life is at risk.

4 Nineteen member states allow early terminations of pregnancy on women's request, and no legal indication is required for early termination (as is required in groups 1-3): Austria (1974), Belgium (1990), Bulgaria (1956/ 1990), the Czech Republic (1957/1987), Denmark (1973), Estonia (1955/1998/2009), France (1975/2001), Germany (1992/1995), Greece (1978/1986), Hungary (1953/1992), Italy (1978), Latvia (1955/2002), Lithuania (1955/1994), the Netherlands (1981), Portugal (2007), Romania (1996), the Slovak Republic (1957/1991), Slovenia (1977/ 1991), and Sweden (1974).

The gestational age limit for a termination of pregnancy on request is 10-14 weeks of gestation in most of the member states, except in Sweden (18 weeks of gestation).
In 14 member states, the upper gestational age for termination of pregnancy associated with fetal indication is either defined between 20 and 24 weeks of gestation or is defined according to fetal viability. However, there are no legal upper limits in 11 countries. In cases of maternal health indications, countries have either an upper gestational limit between 21 and 24 weeks of gestation (nine countries) or no legal restrictions (17 countries) in their legislation. In most countries, however, late-stage terminations of pregnancy are not defined as terminations, but are instead recorded as preterm births. The legislation on terminations of pregnancy and the registration criteria for births does not usually state clear time limits, and the final decision is left to the clinician.

Spousal authorisation for termination of pregnancy is not required in any EU member state, but parental consent for minors is requested in 13 countries: the Czech Republic, Denmark, Estonia, Greece, Hungary, Italy, Latvia, Lithuania, Luxembourg, Poland, Portugal, the Slovak Republic, and Sweden. The definition for being a minor varies in these countries from an upper age limit of 15-18 years.

Termination of pregnancy with medicines (without surgery) is not legally allowed in Hungary, Lithuania, Poland, Romania, and the Slovak Republic, and thus only surgical procedures are available in these five countries.

\section{Rates of terminations of pregnancy}

The 24 EU member states with information on legal terminations of pregnancy report annually approximately 1.2 million terminations, representing 10.3 terminations per 1000 women aged 15-49 years (Figure 1; Table 1). Excluding Ireland, Malta, and Poland, which have no or very restrictive access to termination of pregnancy, the overall rate was 11.3 per 1000 women. The lowest figures were reported in Germany and Greece (about 6/1000 women of reproductive age), and in Belgium, the Netherlands and Portugal (about 7.5/1000). Three countries - Bulgaria, Romania and Estonia - had a rate of 20 or more per 1000 .

Countries allowing terminations of pregnancy on request did not have a higher termination of pregnancy rate (11.0/ 1000 women, with a country variation from 6 to 25 per 1000 women) than countries requiring a legal indication for the termination (12.3/1000 women, ranging from 9 to 14 per 1000 women).

\section{Trends}

To study secular trends in the termination of pregnancy rates, we divided all $\mathrm{EU}$ member states with access to termination of pregnancy into three groups according to their geopolitical and cultural characteristics. By region (Figure 2), Southern Europe had lower rates (8.9/1000) than Central and Eastern Europe (10.8/1000), and Northern Europe (10.9/1000). Since 2000, the rates of 


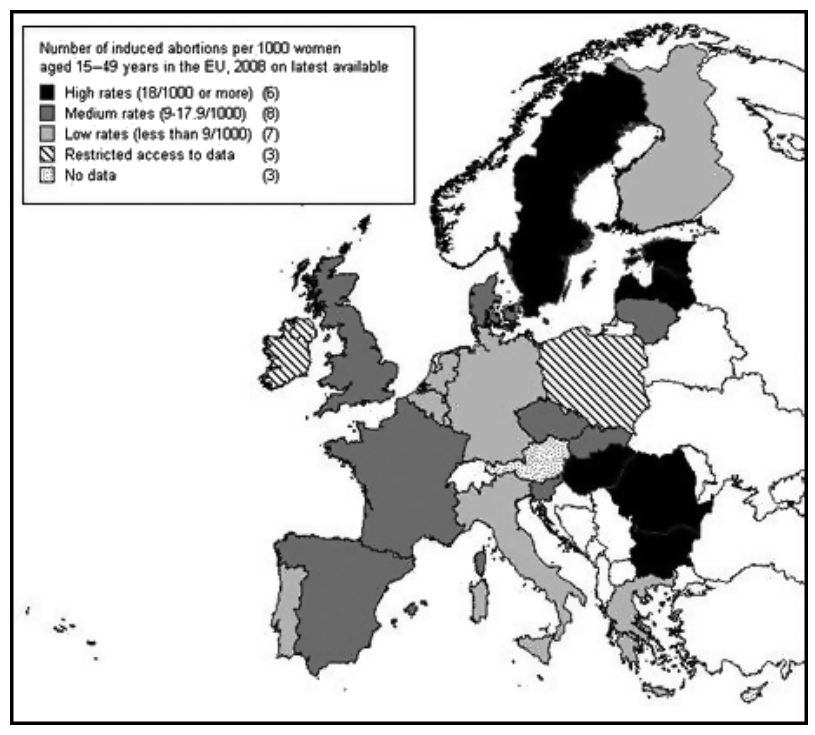

Figure 1. Terminations of pregnancy per 1000 women aged 15-49 years in the EU member states in 2008 , or from most recent available data, according to national or international sources. ${ }^{11-13}$

termination of pregnancy have increased by $5 \%$ in Northern Europe and by $11 \%$ in Southern Europe, but have decreased by $40 \%$ in Central and Eastern Europe.

The regional differences in the termination of pregnancy rates were substantially larger in 1990 (Figure 2), but the differences have since diminished. Since then, the termination rates have decreased by $15 \%$ in Northern Europe and by $88 \%$ in Central and Eastern Europe, but have increased by $14 \%$ in Southern Europe.

The dramatic decline in the rates in Central and Eastern Europe is mostly related to secular trends in Romania and Poland. Romania had a restrictive legislation until 1989. The legal liberalisation of terminations of pregnancy was followed by a five-fold increase in reported termination rates in 1990, followed by a rapidly decreasing trend. Poland had a low rate of termination of pregnancy (15/1000) compared with other Central and Eastern European countries in the 1980s, and the rate of reported legal terminations decreased to below $0.1 / 1000$ after adopting a restrictive legislation in 1993. Excluding Poland, the most recent rate of terminations of pregnancy increased from 10.8 to 17.4 per 1000 women aged $15-49$ years in Central and Eastern Europe.

\section{Subgroups}

According to the most recent statistical data, every ninth termination of pregnancy (14.1\%) in the EU was performed among women aged $<20$ years (Table 2). This proportion for terminations in teenagers was higher in Northern Europe (17\%) than in Central and Eastern Europe (11\%), and in Southern Europe (10\%). In total,
Table 1. The number of reported terminations of pregnancy per 1000 women aged 15-49 years in the European Union (2008 or latest available data)

\begin{tabular}{|c|c|c|c|c|}
\hline & $\begin{array}{l}\text { Number of } \\
\text { abortions }\end{array}$ & Year & Source & $\begin{array}{c}\text { Per } 1000 \\
\text { women } \\
\text { aged 15-49 } \\
\text { years }\end{array}$ \\
\hline \multicolumn{5}{|c|}{ Prohibited (excluding to save woman's life) } \\
\hline Ireland & 0 & & & 0.0 \\
\hline Malta & 0 & & & 0.0 \\
\hline \multicolumn{5}{|c|}{ Allowed for indications related to physical health } \\
\hline Poland & 506 & 2008 & International & 0.1 \\
\hline \multicolumn{5}{|c|}{ Allowed for indications related to physical and mental health } \\
\hline Spain & 115812 & 2008 & International & 10.1 \\
\hline \multicolumn{5}{|c|}{$\begin{array}{l}\text { Allowed for indications related to physical and mental health } \\
\text { and socio-economic grounds }\end{array}$} \\
\hline Finland & 10427 & 2008 & International & 8.9 \\
\hline $\begin{array}{l}\text { UK (excluding } \\
\text { Northern } \\
\text { Ireland) }\end{array}$ & 209191 & 2008 & International & 14.2 \\
\hline \multicolumn{5}{|c|}{ Allowed on request } \\
\hline Belgium & 18595 & 2008 & International & 7.5 \\
\hline Bulgaria & 36593 & 2008 & International & 20.0 \\
\hline Czech Republic & 25760 & 2008 & International & 10.2 \\
\hline Denmark & 16394 & 2008 & National data & 13.2 \\
\hline Estonia & 8420 & 2008 & International & 25.1 \\
\hline France & 213380 & 2007 & National data & 14.3 \\
\hline Germany & 114484 & 2008 & International & 6.0 \\
\hline Greece & 16495 & 2005 & International & 6.1 \\
\hline Hungary & 44089 & 2008 & International & 18.4 \\
\hline Italy & 121301 & 2008 & National data & 8.7 \\
\hline Latvia & 10425 & 2008 & International & 18.0 \\
\hline Lithuania & 9031 & 2008 & International & 10.3 \\
\hline the Netherlands & 28470 & 2008 & International & 7.3 \\
\hline Portugal & 18951 & 2009 & National data & 7.3 \\
\hline Romania & 127909 & 2008 & International & 23.4 \\
\hline Slovak Republic & 10869 & 2008 & National data & 7.7 \\
\hline Slovenia & 4946 & 2008 & International & 10.2 \\
\hline Sweden & 38053 & 2008 & International & 18.3 \\
\hline $\begin{array}{l}\text { European } \\
\text { Union total }\end{array}$ & 1200101 & & & 10.0 \\
\hline
\end{tabular}

No data available for Austria, Cyprus, and Luxembourg. International data from references 11-13.

NA, not applicable.

12.0 terminations of pregnancy were reported per 1000 teenagers aged 15-19 years: the rate was higher in Northern Europe (14/1000) than in Southern Europe (9/1000), or in Central and Eastern Europe (9/1000). The highest rates were reported in Sweden, Estonia, and the UK (24/1000), whereas Greece (2/1000), the Slovak Republic, Germany, and Lithuania (6/1000) had the lowest rates.

Every fifth termination of pregnancy (21.2\%) was performed in women aged 35 years or more. This proportion 


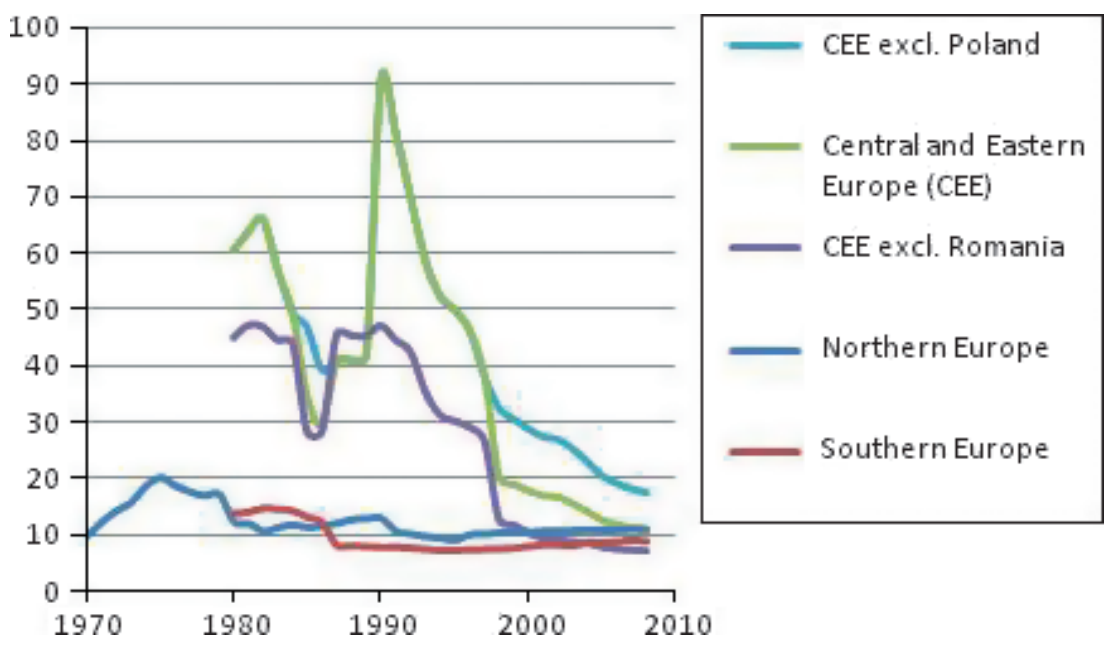

Figure 2. Terminations of pregnancy per 1000 women aged 15-49 years in the EU regions in the period 1970-2008. ${ }^{11-13}$

Table 2. Termination of pregnancies among women aged $<20$ years and aged 35 years or more, per 1000 women aged 15-19/35-49 years, and percentage of all abortions

\begin{tabular}{|c|c|c|c|c|c|c|}
\hline & \multicolumn{3}{|c|}{ Women aged $<20$ years } & \multicolumn{3}{|c|}{ Women aged 35 years or more } \\
\hline & Per 1000 women & $\%$ of all abortions & Year & Per 1000 women & $\%$ of all abortions & Year \\
\hline Belgium & 14.7 & 25.2 & 2008 & 4.4 & 27.5 & 2008 \\
\hline Bulgaria & 17.5 & 10.7 & 2008 & 8.5 & 18.3 & 2008 \\
\hline Czech Republic & 7.9 & 9.6 & 2008 & 6.4 & 25.8 & 2008 \\
\hline Denmark & 15.8 & 17.6 & $2006 / 2008$ & 6.1 & 23.7 & 2006 \\
\hline Estonia & 24.1 & 13.0 & 2008 & 13.2 & 22.3 & 2008 \\
\hline Finland & 12.7 & 19.9 & 2008 & 3.4 & 17.4 & 2008 \\
\hline France & 15.6 & 14.3 & 2007 & 6.8 & 20.8 & 2007 \\
\hline Germany & 6.2 & 12.0 & 2008 & 2.7 & 22.8 & 2008 \\
\hline Greece & 2.3 & 4.1 & 2005 & 4.3 & 31.7 & 2005 \\
\hline Hungary & 17.8 & 12.2 & 2008 & 10.0 & 22.6 & 2008 \\
\hline Italy & 7.2 & 8.6 & 2008 & 5.0 & 28.7 & 2008 \\
\hline Latvia & 14.6 & 11.1 & 2008 & 9.6 & 22.9 & 2008 \\
\hline Lithuania & 6.3 & 8.8 & 2008 & 6.3 & 27.2 & 2008 \\
\hline the Netherlands & 8.3 & 14.4 & 2007 & 3.4 & 22.8 & 2007 \\
\hline Poland & 0.0 & 7.1 & 2006 & 0.0 & 8.3 & 2008 \\
\hline Portugal & 8.4 & 12.2 & 2009 & 3.8 & 30.6 & 2009 \\
\hline Romania & 20.5 & 11.1 & 2008 & 12.8 & 22.5 & 2008 \\
\hline Slovak Republic & 5.6 & 9.7 & 2008 & 5.0 & 26.2 & 2008 \\
\hline Slovenia & 7.8 & 8.5 & 2008 & 6.6 & 29.7 & 2008 \\
\hline Spain & 13.5 & 12.9 & 2008 & 3.9 & 18.0 & 2008 \\
\hline Sweden & 24.4 & 19.9 & 2008 & 8.2 & 20.1 & 2008 \\
\hline UK & 23.8 & 22.1 & 2008 & 4.3 & 14.0 & 2008 \\
\hline Total EU & 14.1 & 12.0 & & 5.2 & 21.2 & \\
\hline Northern Europe & 17.0 & 14.4 & & 4.4 & 19.4 & \\
\hline Southern Europe & 10.4 & 9.1 & & 4.4 & 24.0 & \\
\hline Central and Eastern Europe & 11.0 & 9.2 & & 6.1 & 22.7 & \\
\hline
\end{tabular}

was lower in Northern European countries (19\%) than in Central and Eastern European (23\%), and Southern European countries (24\%). Altogether, 5.2 terminations of preg- nancy were reported per 1000 women aged 35-49 years in the 22 EU member states with available data. The rate was lower in Northern Europe (4/1000) and in Southern 
Europe (4/1000) than in Central and Eastern Europe $(6 / 1000)$. The rates in Hungary, Romania, and Estonia exceeded 10/1000, whereas the rate in Germany was below 3/1000 (Table 2).

Only a few countries were able to provide more information than the total number of terminations of pregnancy and the gestational age-specific rates. Terminations of pregnancy in the second trimester or later were proportionally more common in Spain (11.8\% of all terminations of pregnancy) and Finland (7.3\%). The percentages were lower in other countries that provided data, varying around 3\% in the Czech Republic, Italy, and France, 2\% in Estonia, and $<1 \%$ in the Slovak Republic. Also, in women aged 15-49 years, the rate of terminations of pregnancy in the second trimester and later was the highest in Spain $(1.2 / 1000)$ and Finland (0.7/1000), and the lowest in Italy and the Czech Republic (0.3/1000 for both), as well as the Slovak Republic (0.1/1000), whereas the other countries providing data had a rate of 0.5 per 1000 .

According to the official statistics, of women who terminated their pregnancies, $48 \%$ in France, Belgium, and Spain, 52\% in Finland, and 53\% in Sweden had no previous births. This proportion was lower in Italy $(41 \%)$, Portugal (40\%), Slovenia (34\%), Estonia (29\%), the Czech Republic (28\%), and the Slovak Republic (26\%).

Information on previous terminations of pregnancy was available in eight countries. The proportion of women reporting at least one prior termination was $21 \%$ in Portugal, $27 \%$ in Italy, 33\% in Finland, 35\% in France, 38\% in Sweden, and 39\% in the Czech Republic, but was almost 50\% in Hungary and $62 \%$ in Estonia.

Only a few countries provided information on terminations of pregnancy for women coming from other countries with no or restricted access to termination. England and Wales reported 4600 terminations of pregnancy for Irish women, 38 for Maltese women, and 30 for Polish women in 2008. ${ }^{17}$ There is currently no information on how many Polish or Maltese women receive a termination of pregnancy in other countries.

The Netherlands reported terminations of pregnancy for residents only. ${ }^{18}$ The inclusion of women from other countries increased the official number of terminations of pregnancy by $4513(+15.9 \%)$ in 2008 .

The share of terminations of pregnancy by non-residents was reported by the Slovak Republic $(0.1 \%)$, Finland $(0.2 \%)$, Slovenia $(0.9 \%)$, Belgium $(1.6 \%)$, the UK $(3.4 \%)$, and Portugal $(17.3 \%)$. Excluding non-resident women from the national statistics in Portugal would have decreased their rate of terminations of pregnancy to the same level reported for Greece and Germany, about six per 1000 women aged 15-49 years. Whether all terminations or only terminations for resident women are included in the statistics remains unclear.

\section{Discussion}

Our data shows that the regional differences in official termination of pregnancy rates have decreased in the EU. The improved availability of effective contraceptives, reproductive health services, and better sexual health education in schools may explain this trend, together with converging social norms related to contraception and childbearing. ${ }^{19}$ Nonetheless, the results indicate persistent and significant, up to four-fold, differences in the rates of termination of pregnancy among the $22 \mathrm{EU}$ member states offering a legal termination of pregnancy and providing national statistics. By region, Central and Eastern European and Northern European countries ( 11 per 1000 women aged 15-49 years) had slightly higher rates than Southern European countries (9/1000). The EU averages (14 and 12 per 1000 women aged 15-44 years) remained lower than those reported in 2003 and 2008 for North America (20 and 19 per 1000 women) and Oceania (19 and 18 per 1000 women)..$^{20,21}$

Countries with unrestricted access to early termination of pregnancy $(11 / 1000)$ did not report higher rates than countries with more restricted access (12/1000). Further analysis based on the collection of new data is needed to investigate how the role of organisation of healthcare services and the organisation of abortion services specifically affect the termination rates. Our preliminary analysis suggests that countries with either private-for-profit or private-for-non-profit services for terminations (9/1000) had lower rates than countries with publicly supported services $(12 / 1000)$, but this may merely reflect the completeness of reporting.

The highest terminations of pregnancy rates were reported in Central and Eastern Europe, especially in Estonia, Romania, and Bulgaria, with rates of at least double the EU average. According to other studies, access to safe termination of pregnancy has been reported to have deteriorated in some Central and Eastern European countries because of long distances to services, a lack of services in rural areas, rising costs resulting from the abandonment of insurance coverage for terminations of pregnancy in health insurance or in public health services, the shortage of physicians and gynaecologists, and a deterioration in the quality of abortion services. ${ }^{22}$

Teenage termination of pregnancy rates were higher in Northern European countries (17 per 1000 women aged 15-19 years) than elsewhere (10-11/1000). These higher rates suggest a remaining unmet need for contraceptives among teenagers, even in countries with universal access to sexual and reproductive health services. High teenage termination rates can be reduced by improved access to youth-friendly reproductive and sexual health services, better sexual education in schools, and free or heavily subsidised contraceptives. $^{23}$ 
Women aged 35 years or more had the highest number of terminations of pregnancy in Central and Eastern Europe, which may reflect well-known differences in childbearing patterns. In Northern European countries, many terminations of pregnancy represent unwanted or mistimed pregnancies among young women who wish to postpone childbearing to a more advanced age. In Central and Eastern European and Baltic countries, the mean age of childbearing is still significantly lower than in other parts of the $\mathrm{EU}^{24}$ and more terminations of pregnancy are performed after the preferred family size has been reached. These secular region-specific patterns must be taken into consideration when planning national and European programmes for improving sexual and reproductive health, as well as for reducing the number of unwanted pregnancies. Many of the observed differences probably reflect the variation in secular trends surrounding the formation of families and the family structure desired, which are related to the remaining socio-economic differences across Europe.

Information on terminations of pregnancy was available for the vast majority of countries. Three countries, however, did not have any data or even estimates on their numbers. It is essential to build national reporting systems in Austria, Cyprus, and Luxembourg. The data for countries with restricted access to termination of pregnancy (Ireland, Malta, and Poland) did not cover terminations performed in other countries or illegal terminations, for example in private clinics. The true rates for these countries are likely to be much higher than those presented here.

The quality of the international statistics on terminations of pregnancy is not well studied. For most countries, the figures provided by the national contacts were the same or very similar compared with the figures found in international statistics. The only exception was the Slovak Republic, for which the national data gave lower estimates. The discrepancy arose from the fact that Eurostat and WHO data on terminations also included spontaneous abortions and ectopic pregnancies. An unambiguous definition for 'abortion' should be added to the international data sources, and a clear distinction should be made between terminations of pregnancy (induced abortions) and miscarriages and early fetal losses. Finally, there is no information on whether the induction of menstruation (evacuation of uterus without pregnancy test) is used and included in the statistics.

We used data on legal terminations of pregnancy reported to national information systems. Thus, the reliability of the data on terminations of pregnancy is likely to vary, depending on the completeness of the reporting system. There are only sporadic reports confirming good coverage of statistics on terminations of pregnancy. ${ }^{25}$ Older statistics in France, Germany, Italy, and Poland may be underestimations, ${ }^{26}$ but the data collection systems on terminations of pregnancy, for example in France and Italy, ${ }^{27,28}$ have improved since then. A recent global report used correction factors from 1.05 to 3.00 to provide more reliable national estimates, ${ }^{20}$ but no correction factors were published for the EU member states. National statistics on terminations of pregnancy in Romania, Ireland, Spain, ${ }^{20}$ and Greece ${ }^{29}$ have been reported to be too low according to national and international sources. The European statistical system should expand its quality reporting to data on terminations of pregnancy to get more detailed information on the coverage of the current reporting.

It remains unclear if all terminations of pregnancy or only a portion of them were included in the statistics. In countries with very strict legislation, illegal terminations of pregnancy may be common but unreported. Some national information systems only include total coverage for the public sector, which means that terminations of pregnancy in private hospitals and clinics may not be counted, or they may be under-reported in the national statistics. Some countries (e.g. Finland ${ }^{25}$ ) that require legal indications and/ or permission for termination use the registration of terminations as a control measure. This may result in more comprehensive reporting. These limitations related to coverage of national reporting systems may have affected our trend and country comparisons.

There are no clear guidelines for including temporary migrants and visitors in the national health information systems. For most countries, this did not affect the national figures on terminations of pregnancy. In Portugal, however, the termination rate decreased by more than one-sixth after taking out the terminations of pregnancy performed for non-resident women. The rate for the Netherlands, on the other hand, increases by one-sixth if non-residents are included in the national statistics.

\section{Conclusions}

Whereas the provision of access to reliable and affordable contraception is essential for good sexual and reproductive health, access to safe and affordable termination of pregnancy is still sometimes required. ${ }^{15}$ Women in the EU have different access facilities to terminations of pregnancy. Regional differences in termination of pregnancy still exist, although the rates have decreased during the two last decades. Large variation between countries suggests that rates of termination of pregnancy are not dependent on restrictive legislations. More consistent and coherent reporting of termination of pregnancy is, however, needed to validate the current trends based on heterogeneous data collection systems. Data should also be collected to ascertain how often women have to cross country borders to access a termination of pregnancy. ${ }^{15}$ 
Finally, statistics and information on trends in terminations of pregnancy should be a part of the European Public Health Monitoring System, which the EU Commission is now building up. ${ }^{30}$ The topic-specific public health reporting should include sexual and reproductive health indicators. ${ }^{1,2}$

\section{Disclosure of interests}

The authors have no competing interests to declare.

\section{Contribution to authorship}

MG and IF collected the data. MG wrote the first draft, which was commented upon and revised by AJ, HK, CM, MOdS, JO, CS-V, MT, and EH. All authors have read and accepted the final version of the article.

\section{Details of ethics approval}

Only statistical data was used, and no ethical approval was required for the study.

\section{Funding}

The REPROSTAT 3 (The State of Reproductive Health and Fertility in the European Union) project has been funded by the Health Programme of DG Health and Consumers at the European Commission and High Commissariat of Health, Ministry of Health, Portugal.

\section{Acknowledgements}

The REPROSTAT 3 (The State of Reproductive Health and Fertility in the European Union) project has been funded by the Health Programme of DG Health and Consumers at the European Commission and High Commissariat of Health, Ministry of Health, Portugal. The following people have participated in the project: Christoph Brezinka, Austria; Stanley Luchters and Marleen Temmerman, Belgium; Todor Chernev, Bulgaria; Maria Epaminonda, Cyprus; Vit Unzeitig, the Czech Republic; Jørn Olsen, Denmark; Helle Karro, Estonia; Mika Gissler and Elina Hemminki, Finland; Caroline Moreau, France; Albrecht Jahn, Germany; Evangelos Makrakis, Greece; György Bártfai and Marta Szucs, Hungary; Mary Short, Ireland; Serena Donati, Italy; Inese Birzule, Latvia; Aušra Armonavičiene, Lithuania; Catherine Chéry, Luxembourg; Charles Savona-Ventura, Malta; Medard Lech, Poland; Miguel Oliveira da Silva and Inês Fronteira, Portugal; Valentina Mihaila, Romania; Gabriel Bianchi, The Slovak Republic; Bojana Pinter, Slovenia; Agustin Montés, Spain; Gunilla Lindmark, Sweden; Kitty Bloemenkamp, the Netherlands; Philip Hannaford, UK; and Gunta Lazdane, WHO Regional Office for Europe. Also Vladimír Cupaník from the Slovak Republic and Tamara Georgiadou from Cyprus provided information on terminations of pregnancy in their country for this article. We thank Mr Antti Tuomi-Nikula (THL National Institute for Health and Welfare) for technical help with the map in Figure 1.

\section{Supporting Information}

Additional Supporting Information may be found in the online version of this article:

Appendix S1. Sexual and reproductive health indicators in the EU member states.

Please note: Wiley-Blackwell are not responsible for the content or functionality of any supporting information supplied by the authors. Any queries (other than missing material) should be directed to the corresponding author.

\section{References}

1 Temmerman M, Foster BL, Hannaford P, Cattaneo A, Olsen J, Bloemenkamp K, et al. Reproductive health indicators in the European Union: the Reprostat project. Eur J Obstet Gynecol Reprod Biol 2006;126:3-10.

2 Gissler M, Hannikainen-Ingman K, Donati S, Jahn A, Oliveira da Silva $M$, Hemminki $E$, et al. The feasibility of European reproductive health indicators. Eur J Contracept Reprod Health Care 2008;13: 376-86.

3 Arisi E. Changing attitudes towards abortion in Europe. Eur J Contracept Reprod Health Care 2003;8:109-21.

4 Molinelli A, Picchioni DM, Celesti R. Voluntary interruption of pregnancy in Europe: medico-legal issues and ethical approach to the regulation. Minerva Ginecol 2005;57:217-23.

5 Gissler M, Hemminki E, Kautto M. Late childbearing and low fertility challenge sustainable development. Seminar Report on NOMESCO and NOSOSCO seminar on Sustainable Social and Health Development in the Nordic Countries (pages 50-63). NOMESCO 78: 2006 \& NOSOSCO 29: 2006. Copenhagen 2006.

6 Sobotka T. Is Lowest-Low Fertility in Europe Explained by the Postponement of Childbearing? Population and Development Review 2004;30:195-220.

7 Roemer R. Abortion law: the approaches of different nations. Am J Public Health 1967;57:1906-22.

8 Cook RJ, Dickens BM. International Developments in Abortion Laws: 1977-88. Am J Public Health 1988;78:1305-11.

9 Boland R, Katzive L. Developments in laws on induced abortion: 1998-2007. Int Fam Int Fam Plan Perspect 2008;34:110-20.

10 Thornton A, Philipov D. Sweeping changes in marriage, cohabitation, and childbearing in central and eastern europe: new insights from the developmental idealism framework. Eur J Popul 2009;25: $123-56$.

11 Eurostat. Declared legal abortions by age. [http://appsso.eurostat. ec.europa.eu/nui/show.do?dataset=demo_fabort\&lang=en.]. Accessed 7 October 2011

12 WHO Regional Office for Europe. Health for all - statistical database. [www.euro.who.int/hfadb]. Accessed 10 July 2010.

13 United Nations. Population and vital statistics report. http://unstats. un.org/unsd/demographic/sconcerns/health/hel2.htm. Accessed 7 October 2011.

14 Eurostat. Population on 1. January by age and sex. [http:// appsso.eurostat.ec.europa.eu/nui/show.do?dataset=demo_pjan\&lang =en]. Accessed 7 October 2011. 
15 The Reproductive Health Report. The state of sexual and reproductive health within the European Union. Eur I Contracept Reprod Health Care 2011;16 (Suppl 1):S1-70.

16 IPPF European Network. Abortion legislation in Europe. International planned parenthood federation. January 2009 update. [www.ippfen. org/NR/rdonlyres/DB347D31-0159-4C7D-BE5C-428623ABCA25/0/Pub_ AbortionlegislationinEuropeIPPFEN_Feb2009.pdf]. Accessed 7 October 2011.

17 Department of Health. Statistics on Induced abortions in England and Wales 2008. Statistical Bulletin 1/2009. [www.dh.gov.uk/ en/Publicationsandstatistics/Publications/PublicationsStatistics/DH_ 099285]. Accessed 7 October 2011.

18 Staatstoezicht op de Volksgezondheid: Jaarrapportage 2008 van de Wet afbreking zwangerschap (Annual report on the Law on pregnancy termination 2008). Den Haag 2009.

19 Teitler J. Trends in Youth Sexual Initiation and Fertility in Developed Countries: 1960-1995. Ann Amer Acad Polit Soc 2002;580:134-52.

20 Sedgh G, Henshaw S, Singh S, Ahman E, Shah $\mathrm{H}$. Induced abortion: estimated rates and trends worldwide. Lancet 2007;370:1338-45.

21 Sedgh G, Singh S, Henshaw SK, Bankole A. Legal abortion worldwide in 2008: levels and recent trends. Int Perspect Sex Reprod Health 2011;37:84-94.

22 Hodorogea S, Comendant R. Prevention of unsafe abortion in countries of Central Eastern Europe and Central Asia. Int J Gynaecol Obstet 2010;110 (Suppl):S34-7.
23 Kosunen E, Vikat A, Gissler M, Rimpelä M. Teenage pregnancies and abortions in Finland in the 1990s. Scand J Public Health 2002;30:300-5.

24 EURO-PERISTAT. European Perinatal Health Report - better statistics for better health for pregnant women and their babies. Paris. 2008. [www.europeristat.com/publications/european-perinatal-health-report. shtml]. Accessed 7 October 2011.

25 Gissler M, Ulander V-M, Hemminki E, Rasimus A. Declining induced abortion rate in Finland: data-quality of the Abortion Register. Int J Epidemiol 1996;25:376-80.

26 David HP. Abortion in Europe 1920-1991: a public health perspective. Stud Fam Plan 1992;23:1-22.

27 Rossier C, Toulemon L, Prioux F. Abortion Trends in France, 19902005. Population-E, 64/2009, pages 443-476.

28 Relazione del Ministro della salute sulla attuazione della legge contenente norme per la tutela sociale della maternità e per l'interruzione volontaria di gravidanza (Legge 194/78) - Dati preliminari 2009, dati definitivi 2008. (In Italian: Preliminary data 2009, final data 2008) Agosto2010.

29 Ioannidi-Kapolou E. Use of contraception and abortion in Greece: a review. Reprod Health Matters 2004;12 (24 Suppl):174-83.

30 Kilpeläinen K, Aromaa A and the ECHIM Core Group (editors). European Health Indicators: Development and Initial Implementation. Final Report of the ECHIM Project. National Public Health Institute. Publications B31: 2008. Helsinki 2008. 